\title{
Identification of differentially expressed genes and biological pathways in bladder cancer
}

\author{
FUCAI TANG ${ }^{1,2}$, ZHAOHUI HE ${ }^{1,2}$, HANQI LEI ${ }^{1,2}$, YUEHAN CHEN $^{3}$, \\ ZECHAO LU ${ }^{4}$, GUOHUA ZENG ${ }^{1,2}$ and HANGTAO WANG ${ }^{1,2}$ \\ ${ }^{1}$ Department of Urology, Minimally Invasive Surgery Center, The First Affiliated Hospital of Guangzhou Medical University; \\ ${ }^{2}$ Guangdong Key Laboratory of Urology, Guangzhou, Guangdong 510230; ${ }^{3}$ Nanshan College of Guangzhou Medical University; \\ ${ }^{4}$ The First Clinical College of Guangzhou Medical University, Guangzhou, Guangdong 511436, P.R. China
}

Received August 30, 2017; Accepted March 2, 2018

DOI: $10.3892 / \mathrm{mmr} .2018 .8711$

\begin{abstract}
The purpose of the present study was to identify key genes and investigate the related molecular mechanisms of bladder cancer (BC) progression. From the Gene Expression Omnibus database, the gene expression dataset GSE7476 was downloaded, which contained $43 \mathrm{BC}$ samples and 12 normal bladder tissues. GSE7476 was analyzed to screen the differentially expressed genes (DEGs). Gene Ontology (GO) and Kyoto Encyclopedia of Genes and Genomes (KEGG) pathway analyses were performed for the DEGs using the DAVID database, and a protein-protein interaction (PPI) network was then constructed using Cytoscape software. The results of the GO analysis showed that the upregulated DEGs were significantly enriched in cell division, nucleoplasm and protein binding, while the downregulated DEGs were significantly enriched in 'extracellular matrix organization', 'proteinaceous extracellular matrix' and 'heparin binding'. The results of the KEGG pathway analysis showed that the upregulated DEGs were significantly enriched in the 'cell cycle', whereas the downregulated DEGs were significantly enriched in 'complement and coagulation cascades'. JUN, cyclin-dependent kinase 1, FOS, PCNA, TOP2A, CCND1 and CDH1 were found to be hub genes in the PPI network. Sub-networks revealed that these gene were enriched in significant pathways, including the 'cell cycle' signaling pathway and 'PI3K-Akt signaling pathway'. In summary, the present study identified DEGs and key target genes in the progression of $\mathrm{BC}$, providing potential molecular targets and diagnostic biomarkers for the treatment of $\mathrm{BC}$.
\end{abstract}

Correspondence to: Dr Zhaohui He, Department of Urology, Minimally Invasive Surgery Center, The First Affiliated Hospital of Guangzhou Medical University, 1 Kangda Road, Haizhou, Guangzhou, Guangdong 510230, P.R. China

E-mail: gzgyhzh@163.com

Key words: bioinformatics analysis, bladder cancer, differentially expressed genes, enrichment analysis, protein-protein interaction

\section{Introduction}

Bladder cancer (BC) is the fourth most common cancer in men and the seventh most common solid tumor in women worldwide, with an estimated 430,000 new cases diagnosed in $2012(1,2)$. While the incidence rate is stable or declining in men, it exhibits an increasing trend in women (3). BC has a complex biological behavior, with frequent relapse and metastasis (4). Previous data shows that about one-third of initial BC cases will exhibit local progression and distant metastasis, and the 5-year survival rate is $<62 \%$ (5). However, the mechanism underlying $\mathrm{BC}$ is not clear, and the mechanisms of occurrence, recurrence and metastasis are still unknown. Therefore, it is of great value to explore the molecular mechanisms involved in the apoptosis, proliferation, metastasis and invasion of $\mathrm{BC}$ for the improvement of prevention, diagnosis and therapy.

The histopathology and molecular pathways in BC pathogenesis have been described. Somatic copy number alterations in multiple regions have been identified in previous studies, including amplification of PPARG and E2F3, with loss of CDKN2A and RB1 (6,7). The Cancer Genome Atlas (TCGA) project reported that potential therapeutic targets had been identified in $69 \%$ of the bladder tumors investigated; $42 \%$ of the tumors were reported to have targets in the phosphatidylinositol-3-OH kinase/AKT/mTOR pathway, and 45\% were reported to have targets in the RTK/MAPK pathway (8). So far, knowledge of the molecular biology of $\mathrm{BC}$ has lagged behind that of other cancers. No molecular or gene-targeting agents have been approved for the treatment of the disease. Therefore, understanding the molecular mechanism of $\mathrm{BC}$ is vital for the development of more precise diagnostic and effective therapeutic strategies.

With the continuous development of bioinformatics and molecular biology, it is possible to explore the mechanism of carcinogenesis and development at the molecular level. In previous decades, a large number of important signaling pathways in tumorigenesis were identified through analysis of the expression profiles of gene microarrays. This technology has also been used for genomic analysis, which may aid in the discovery of key genes that are interrelated with tumorigenesis (9).

In the present study, a gene expression profile (GSE7476) was downloaded from the Gene Expression Omnibus database 
(GEO). The differentially expressed genes (DEGs) between the controls and $\mathrm{BC}$ samples were analyzed. Gene Ontology (GO) and Kyoto Encyclopedia of Genes and Genomes (KEGG) analyses in the DAVID database were applied to analyze the functional enrichment and significant pathways associated with the DEGs. In addition, we constructed a PPI network to identify the critical DEGs and significant modules. This study aimed to investigate the involvement of genes critical to BC, and to promote the development of novel targeted agents for $\mathrm{BC}$ therapeutic intervention.

\section{Materials and methods}

Microarray data. Gene expression profiles for BC (GSE7476) were downloaded from the GEO on the NCBI website (http://www.ncbi.nlm.nih.gov/geo). The probe-level data were converted into the corresponding gene symbols to detect the expression of gene transcript levels, according to the annotation information downloaded from the platform GPL570 (Affymetrix Human Genome U133 Plus 2.0 Array), which contains 54,675 probes. The gene expression profiles consisted of 12 urothelial samples from patients with prostatic hyperplasia or renal failure with no evidence of bladder malignancy, and 43 tumor samples from different BC risk groups. The mean age of the $\mathrm{BC}$ risk groups, which consisted of 39 males and 4 females, was 77 years (10). In total, 15 low-grade superficial tumor samples, 13 high-grade superficial tumor samples and 15 high-grade muscle-invasive tumors samples were assigned to the BC risk group (10). The healthy control (HC) group, which comprised 12 males, had a median age of 59 years (10). The datasets from the $12 \mathrm{HC}$ and $43 \mathrm{BC}$ samples were analyzed.

Data processing and screening of DEGs. The CEL file data of GSE7476, downloaded from the GEO database, were read using the affy package in the $\mathrm{R}$ programming language (R). The original probe-level data were converted into gene symbols. Then, the expression values of multiple probes for the same gene were transformed into a single value by taking the mean expression value. The RMA method (robust multiarray average) was applied to carry out data pre-processing, including background correction, normalization and expression calculation of the original array data. The Limma package in R (11) was used to identify the DEGs between BC and HC samples. The Benjamini-Hochberg (BH) method (12) was introduced to adjust the raw P-values into a false discovery rate (FDR) to avoid the multi-test problem, which might produce too many false positive results. $\mathrm{P}<0.05$ and $\log _{2}$ fold change $(\mathrm{FC}) \mid \geq 1$ were set as the thresholds for identifying DEGs.

Functional and pathway enrichment analysis of DEGs. GO and KEGG analyses were applied for the functional annotation and pathway analysis, using the Database for Annotation Visualization and Integrated Discovery (DAVID; https://david. ncifcrf.gov/) (13). The human genome was selected as the background parameter. $\mathrm{P}<0.05$ and a count $\geq 2$ were set as the thresholds to indicate a statistically significant difference.

PPI network construction and analysis of modules. PPI analyses may be helpful in identifying the generic organizational principles of functional networks, and to provide

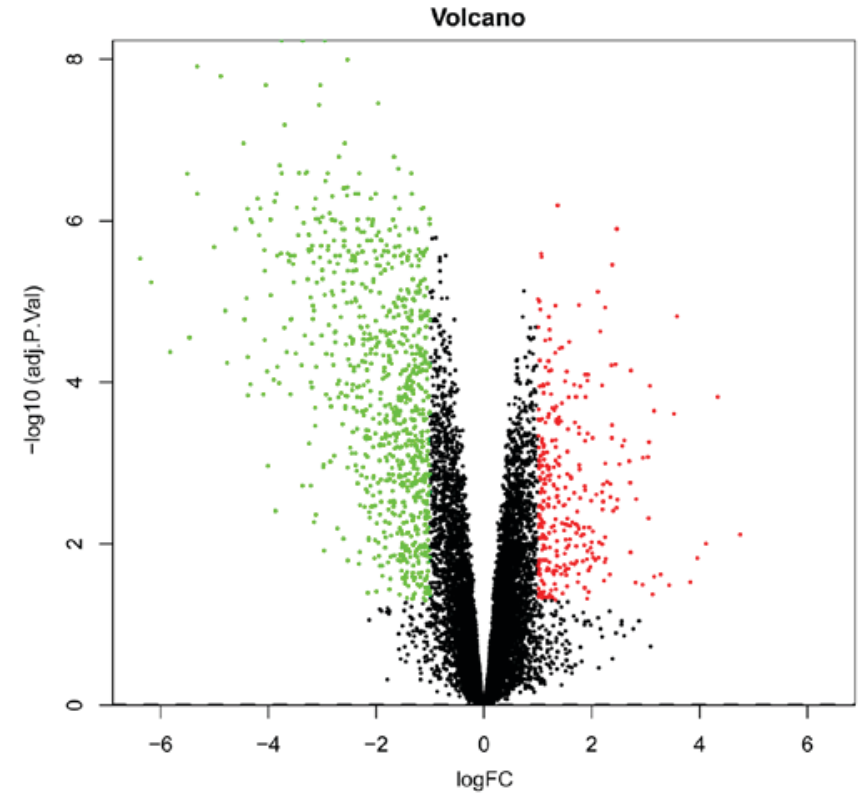

Figure 1. Volcano plot of the DEGs. The abscissa represents $\log \mathrm{FC}$ and the ordinate represents- $\log _{10}$ (P-value). The red and green dots indicate DEGs, while the black dots represent genes that are not differentially expressed between bladder cancer and healthy control tissues. Red, upregulation; green, downregulation. DEG, differentially expressed gene; FC, fold-change.

novel insights into protein function (14). In order to reveal the functional associations between proteins on a genome-wide scale, the STRING database (http://string-db.org/) online software $(15,16)$ was used to construct a PPI network.

PPI networks were created after all DEGs were imported into the Cytoscape plugin. Confidence score $\geq 0.4$ was set as the cut-off criterion. Molecular Complex Detection (MCODE) (17) was then applied to conduct module analysis in the resulting PPI network with the following parameters: Node score cutoff, $\geq 2$; degree cutoff, $\geq 2$; max depth, 100 ; and K-core, $\geq 2$.

\section{Results}

Data preprocessing and DEG screening. The RNA was isolated from the tissue from $\mathrm{BC}$ and $\mathrm{HC}$ samples, respectively, for use in the microarray studies. A total of 20,487 gene symbols were discerned and the gene expression matrix of the samples was obtained. Based on the $\mathrm{R}$ analysis, a total of 1,173 DEGs were identified in $\mathrm{BC}$ compared with $\mathrm{HC}$ samples, including 859 upregulated genes and 314 downregulated genes. $\mathrm{P}<0.05$ and $|F C| \geq 2.0$ were set as the threshold criteria. The top 10 upregulated DEGs and top 10 downregulated DEGs are listed in Table I. A volcano plot of the DEGs is presented in Fig. 1.

Functional and pathway enrichment analysis of DEGs. To further explore the systematic characterization and biological functions of the identified DEGs, functional annotation and pathway analysis, including GO and KEGG, were performed using DAVID.

In this study, the three GO categories [cellular component (CC), biological process (BP) and molecular function MF)] were detected, respectively, using DAVID. The top 15 GO terms of the upregulated and downregulated DEGs are shown in Table II and Fig. 2, respectively. The upregulated 
Table I. Top ten upregulated and downregulated differentially expressed genes between bladder cancer and normal tissues.

A, The top 10 upregulated differentially expressed genes

\begin{tabular}{|c|c|c|c|c|c|c|}
\hline Gene symbol & $\log \mathrm{FC}$ & AveExpr & $\mathrm{t}$ & P-value & adj.P.Val & B \\
\hline DPP3 & 1.367807192 & 6.823383737 & -15.62834787 & 1.34E-09 & $6.41 \mathrm{E}-07$ & 12.55923385 \\
\hline PAFAH1B3 & 2.465494694 & 7.611594612 & -14.08412651 & 4.65E-09 & $1.26 \mathrm{E}-06$ & 11.35210194 \\
\hline TFPT & 1.064195524 & 6.593293201 & -12.69386019 & $1.58 \mathrm{E}-08$ & $2.55 \mathrm{E}-06$ & 10.14074068 \\
\hline RANGAP1 & 1.069859311 & 6.672884639 & -12.47693921 & $1.93 \mathrm{E}-08$ & 2.81E-06 & 9.939786046 \\
\hline IGFBP3 & 2.382533743 & 10.63365369 & -12.1139983 & 2.73E-08 & $3.49 \mathrm{E}-06$ & 9.59578721 \\
\hline PVRL4 & 2.113260416 & 7.562648025 & -11.09448808 & 7.52E-08 & $7.52 \mathrm{E}-06$ & 8.574037157 \\
\hline SEC61A1 & 1.001492679 & 8.052241965 & -10.79227308 & $1.03 \mathrm{E}-07$ & 9.34E-06 & 8.254355505 \\
\hline MTFP1 & 1.022940775 & 6.246895347 & -10.71273652 & $1.12 \mathrm{E}-07$ & 9.91E-06 & 8.168871656 \\
\hline ESRP1 & 1.760663741 & 8.297155088 & -10.59987707 & $1.27 \mathrm{E}-07$ & $1.10 \mathrm{E}-05$ & 8.046588009 \\
\hline ABRACL & 1.327112508 & 7.101266084 & -10.57221373 & $1.30 \mathrm{E}-07$ & $1.12 \mathrm{E}-05$ & 8.016436726 \\
\hline
\end{tabular}

B, The top 10 downregulated differentially expressed genes

\begin{tabular}{|c|c|c|c|c|c|c|}
\hline Gene symbol & $\log \mathrm{FC}$ & AveExpr & $\mathrm{t}$ & P-value & adj.PVal & B \\
\hline SCARA5 & -3.36100537 & 4.768657761 & 30.97352259 & $3.13 \mathrm{E}-13$ & 5.84E-09 & 19.86271169 \\
\hline LINC01082 & -3.753683567 & 5.294466313 & 29.16744989 & $6.59 \mathrm{E}-13$ & 5.84E-09 & 19.29373062 \\
\hline OLFML1 & -2.95576203 & 4.434015195 & 28.55851363 & $8.55 \mathrm{E}-13$ & 5.84E-09 & 19.08956481 \\
\hline TMEM100 & -2.533343457 & 3.70073062 & 26.68801945 & $1.97 \mathrm{E}-12$ & $1.01 \mathrm{E}-08$ & 18.41959434 \\
\hline MIR100HG & -5.32118364 & 4.747251266 & 25.79518302 & $3.01 \mathrm{E}-12$ & $1.23 \mathrm{E}-08$ & 18.07515932 \\
\hline CFD & -4.881864287 & 8.124954765 & 24.85704639 & $4.74 \mathrm{E}-12$ & $1.62 \mathrm{E}-08$ & 17.69452213 \\
\hline SLIT2 & -4.050964305 & 5.040374213 & 23.90645097 & $7.67 \mathrm{E}-12$ & $2.09 \mathrm{E}-08$ & 17.28787436 \\
\hline PRDM6 & -3.036050363 & 4.838278315 & 23.58237834 & $9.07 \mathrm{E}-12$ & 2.09E-08 & 17.14414695 \\
\hline MRGPRF & -4.045214224 & 5.668562294 & 23.55835407 & $9.18 \mathrm{E}-12$ & 2.09E-08 & 17.13338551 \\
\hline LRFN5 & -1.962030571 & 3.960439049 & 22.38800885 & $1.72 \mathrm{E}-11$ & $3.51 \mathrm{E}-08$ & 16.59060679 \\
\hline
\end{tabular}

DEGs were involved in the different GO terms, such as 'cell division' (ontology: $\mathrm{BP}$ ), 'nucleoplasm' (ontology: $\mathrm{CC}$ ) and 'protein binding' (ontology: MF) (Table IIA and Fig. 2A). The most significantly downregulated DEGs were related to the GO terms 'extracellular matrix organization' (ontology: $\mathrm{BP}$ ), 'proteinaceous extracellular matrix' (ontology: CC) and 'heparin binding' (ontology: MF) (Table IIB and Fig. 2B).

Subsequently, KEGG pathway analysis demonstrated that the upregulated DEGs were enriched in five key pathways (Table IIIA and Fig. 3A), including 'cell cycle', 'DNA replication' and 'p53 signaling pathway', whereas the downregulated DEGs were enriched in five different pathways (Table IIIB and Fig. 3B), including 'complement and coagulation cascades', 'focal adhesion' and 'hypertrophic cardiomyopathy (HCM)'.

PPI network construction and module selection. STRING was applied to construct the PPI network of the DEGs. This PPI network consisted of 959 nodes interacting via 6,400 edges. Seven hub genes appeared in the top 10 genes list in terms of degree, betweenness and closeness, simultaneously. Among these genes, Jun proto-oncogene (JUN) showed the highest node degree, which was 144. The others included cyclin-dependent kinase 1 (CDK1, degree=125), Fos proto-oncogene (fos, degree $=122$ ), proliferating cell nuclear antigen (PCNA, degree=101), topoisomerase (DNA) II alpha (TOP2A, degree=100), cyclin D1 (CCND1, degree=98) and cadherin 1 (CDH1, degree=98).

Moreover, 27 functional clusters were selected from the PPI network using MCODE. The top 3 significant modules were selected (Fig. 4), and the pathway enrichment annotation of the genes involved in the modules was analyzed using KEGG pathway analysis, which revealed that the genes in modules 1-3 were mainly associated with the 'cell cycle' signaling pathway (both appearing in module 1 and module 2), and 'PI3K-Akt signaling pathway'.

\section{Discussion}

$\mathrm{BC}$ is one of the most common types of malignant cancer in China and has a high mortality rate (18). BC is the most common form of urinary tract malignant tumor. Approximately $95 \%$ of bladder tumors are urothelial, and their treatment mainly centers around surgery; however, relapse and metastasis after surgery are common (4). The key genes and pathways associated with $\mathrm{BC}$ were identified in the present study using bioinformatics methods.

In the present study, $\mathrm{R}$ was used to extract the genetic information from GSE7476, and a total of 1,173 genes were 
Table II. The top 15 enrichedgene ontology terms of upregulated DEGs and downregulated DEGs.

A, The top 15 enriched gene ontology terms of the upregulated DEGs

\begin{tabular}{llrl}
\hline Category & \multicolumn{1}{c}{ Term } & Count & P-value \\
\hline BP & Cell division & 47 & $2.13 \mathrm{E}-28$ \\
BP & Mitotic nuclear division & 28 & $7.12 \mathrm{E}-15$ \\
BP & sSster chromatid cohesion & 19 & $6.92 \mathrm{E}-14$ \\
BP & G1/S transition of & 17 & $9.83 \mathrm{E}-12$ \\
& mitotic cell cycle & & \\
BP & Cell proliferation & 28 & $7.54 \mathrm{E}-11$ \\
CC & Nucleoplasm & 97 & $6.57 \mathrm{E}-14$ \\
CC & Condensed chromosome & 17 & $6.24 \mathrm{E}-13$ \\
& kinetochore & & \\
CC & Midbody & 19 & $3.04 \mathrm{E}-12$ \\
CC & Spindle pole & 16 & $2.50 \mathrm{E}-10$ \\
CC & Kinetochore & 14 & $5.65 \mathrm{E}-10$ \\
MF & Protein binding & 198 & $6.15 \mathrm{E}-12$ \\
MF & Protein kinase binding & 27 & $4.95 \mathrm{E}-10$ \\
MF & ATP binding & 51 & $5.69 \mathrm{E}-07$ \\
MF & Microtubule binding & 14 & $3.52 \mathrm{E}-05$ \\
MF & Microtubule motor activity & 8 & $3.11 \mathrm{E}-04$ \\
\hline
\end{tabular}

$\mathrm{B}$, The top 15 enriched gene ontology terms of the downregulated DEGs

\begin{tabular}{|c|c|c|c|}
\hline Category & Term & Count & P-value \\
\hline $\mathrm{BP}$ & $\begin{array}{l}\text { Extracellular matrix } \\
\text { organization }\end{array}$ & 45 & $1.92 \mathrm{E}-19$ \\
\hline $\mathrm{BP}$ & Platelet degranulation & 27 & $2.96 \mathrm{E}-13$ \\
\hline $\mathrm{BP}$ & Cell adhesion & 58 & $1.86 \mathrm{E}-12$ \\
\hline $\mathrm{BP}$ & $\begin{array}{l}\text { Muscle organ } \\
\text { development }\end{array}$ & 20 & $9.72 \mathrm{E}-09$ \\
\hline $\mathrm{BP}$ & Muscle contraction & 21 & 4.34E-08 \\
\hline $\mathrm{CC}$ & $\begin{array}{l}\text { Proteinaceous extracellular } \\
\text { matrix }\end{array}$ & 60 & $9.31 \mathrm{E}-26$ \\
\hline $\mathrm{CC}$ & Extracellular matrix & 62 & $5.68 \mathrm{E}-25$ \\
\hline $\mathrm{CC}$ & Extracellular space & 132 & 2.99E-19 \\
\hline $\mathrm{CC}$ & Extracellular region & 145 & $6.81 \mathrm{E}-18$ \\
\hline $\mathrm{CC}$ & Sarcolemma & 26 & $1.01 \mathrm{E}-14$ \\
\hline MF & Heparin binding & 37 & $1.33 \mathrm{E}-16$ \\
\hline MF & Integrin binding & 26 & $1.77 \mathrm{E}-12$ \\
\hline MF & $\begin{array}{l}\text { Extracellular matrix } \\
\text { binding }\end{array}$ & 11 & $5.86 \mathrm{E}-08$ \\
\hline MF & Actin binding & 34 & $1.34 \mathrm{E}-07$ \\
\hline $\mathrm{MF}$ & Calcium ion binding & 62 & 2.85E-07 \\
\hline
\end{tabular}

DEG, differentially expressed gene; $\mathrm{BP}$, biological process; $\mathrm{CC}$, cellular component; MF, molecular function.

identified to be differentially expressed between $\mathrm{BC}$ and $\mathrm{HC}$ samples, among which 314 were upregulated and 859 were downregulated in $\mathrm{BC}$. The upregulated DEGs were mainly enriched in 'cell division', 'nucleoplasm' and 'protein binding', while the downregulated DEGs were mainly involved in 'extracellular matrix organization', 'proteinaceous extracellular matrix' and 'heparin binding'. Moreover, the KEGG pathway enrichment analysis results showed that the upregulated DEGs were associated with the 'cell cycle', 'DNA replication' and the 'p53 signaling pathway', whereas the downregulated DEGs were mainly enriched in the 'complement and coagulation cascades', 'focal adhesion' and 'HCM'.

Previous studies have demonstrated that tumor development is associated with the activation of the coagulation cascade. The exact mechanism through which coagulation proteins promote tumorigenesis remains unclear; however, it is possibly associated with hemostatic factor changes and peritumoral deposition of fibrin (19-21). The cell cycle is the series of events that occur between cell duplication and division, and is closely associated with cell growth, anabolism and proliferation (22). Uncontrolled cell proliferation and DNA replication comprise one of the hallmarks of cancer (23). p53 is known to be mutated in $>50 \%$ of all human cancers, including bladder carcinoma (24). Alterations in p53 expression levels are correlated with tumor recurrence, lower survival rates (25) and poor prognosis in BC patients (26). Therefore, investigating these signaling pathways may aid in elucidating the carcinogenic mechanism of BC.

In addition, a PPI network was constructed to identify the key DEGs. We used proteins that corresponded to genes to construct the PPI network, and found that seven hub genes (JUN, CDK1, FOS, PCNA, TOP2A, CCND1 and CDH1) appeared in each of the top 10 gene lists in terms of degree, betweenness and closeness. JUN and FOS both exhibited downregulated expression, and were identified as main hub genes, with degree values of 144 and 122, respectively. FOS and JUN are proto-oncogenes belonging to the family of activator protein 1 (AP1) transcription factors $(27,28)$. Ye et al (29) reported that AP-1 plays a vital role in cellular migration, metastasis, proliferation, transformation, apoptosis and inflammation. C-FOS, a major member of the FOS family, has been demonstrated to be involved in the regulation of cell growth, differentiation, proliferation, transformation and apoptosis (30). Previous studies have shown that the level of $\mathrm{C}-\mathrm{FOS}$ in BC tissues is significantly higher than that in adjacent non-cancer and normal tissues $(31,32)$. Most of the research on c-Jun (a major member of the JUN family), indicates that it may contribute to tumor initiation and invasiveness $(33,34)$. Huhe et al (35) revealed that high c-Jun expression served a vital role in tumor progression, and may be a diagnostic and therapeutic biomarker in urothelial carcinoma of the bladder.

The results of our study also showed that CCND1 and CDH1 were enriched in several pathways in BC. CCND1, a cell cycle regulatory factor, promotes the progression of the cell cycle through the G1/S phase limit points. Overexpression of the CCND1 gene can result in uncontrolled cell proliferation and tumor occurrence by shortening the G1 phase $(36,37)$. Many patients with cancer have been found to overexpress CCND1, and thus to have a poor prognosis $(38,39)$. Xu et al $(40)$ reported that the expression of CCND1 is associated with the progression of $\mathrm{BC}$; therefore, CCND1 may be considered as an auxiliary diagnostic factor and potential prognostic marker for 
A

Top 15 enriched gene ontology terms of the upregulated DEGs

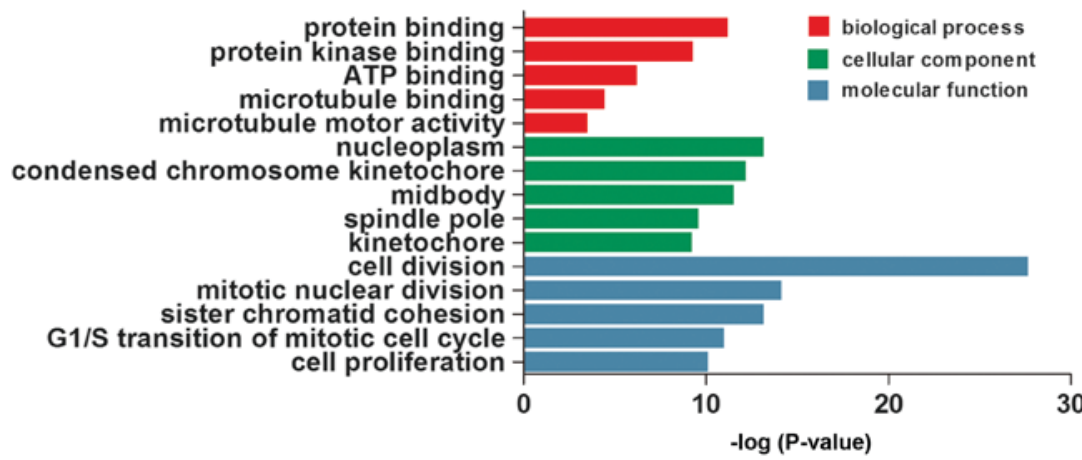

B Top 15 enriched gene ontology terms of the downregulated DEGs

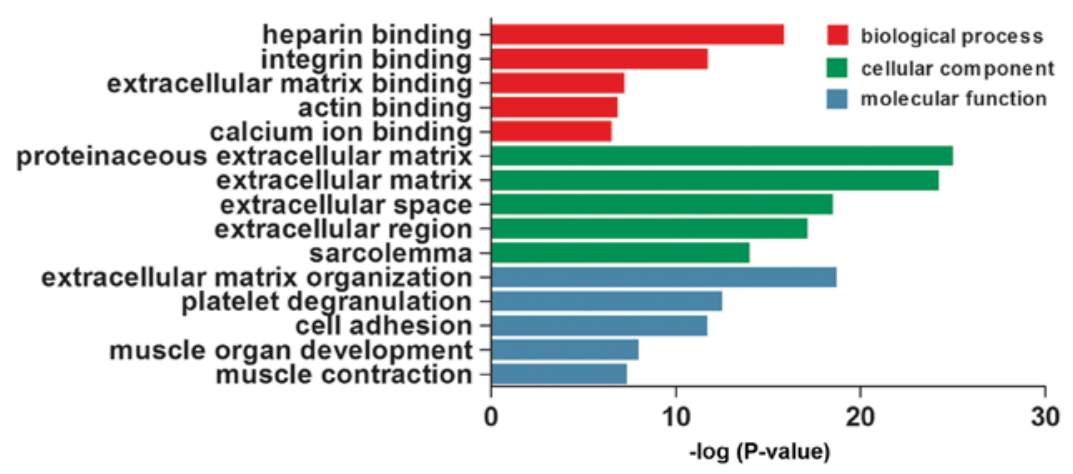

Figure 2. The top 15 enriched Gene Ontology terms of upregulated (A) and downregulated (B) differentially expressed genes. DEG, differentially expressed gene.

A Top 5 enriched pathways of the upregulated DEGs

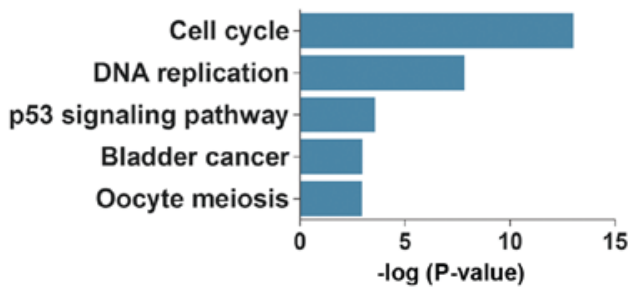

B The top 5 enriched pathways of the downregulated DEGs

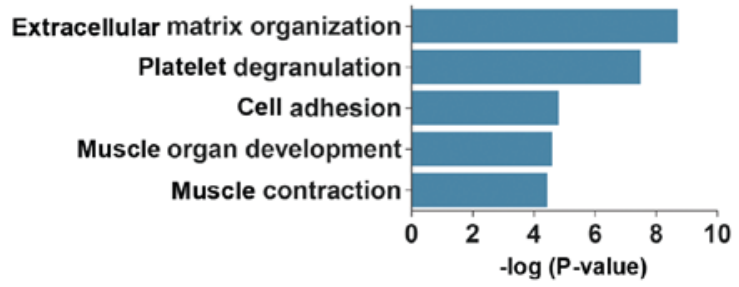

Figure 3. The top five enriched pathways of upregulated (A) and downregulated (B) differentially expressed genes. DEG, differentially expressed gene.

BC patients. CDH1 encodes a classical cadherin of the cadherin superfamily. A previous report (41) showed that CDH1 plays an important role in suppressing the invasive phenotype of urothelial BC cells. Many studies have shown that the classical cadherins and related molecular pathways may be attractive therapeutic targets to restrain tumor progression in patients with BC (42-46).

Cell cycle progression is controlled by cyclin-dependent kinases (CDKs) and cyclins. Cell cycle dysregulation may lead to uncontrolled cell proliferation and the subsequent development of cancer (47). CDK1 regulates the G1-S transition in the cell cycle, a process that is important for the development of centrosome mutation (48). CDK1 is a vital regulator in cell proliferation, and overexpression may lead to high tumor aggressiveness and poor prognosis (49-51). Some antibodies, including anti-CDK1, have been used to investigate cell proliferation (52). One study revealed that determination of the specific activity of CDK1 may be useful in the prediction of outcomes in breast cancer patients (53). Therefore, CDK1 may also play an important role in BC tumorigenesis, and further study is required to identify whether it may serve as a potential molecular marker associated with $\mathrm{BC}$.

PCNA, which encodes a nuclear protein that functions as a cofactor of DNA polymerase delta, serves as an important proliferative marker in carcinogenesis (54). The synthesis rate of PCNA has a direct impact on the proliferative rate of cells (55). An early study reported that significant clinical information obtained from immunohistochemical staining for PCNA may be helpful in the initial selection of therapies and the evaluation of chemotherapeutic effects (56). Malkas et al (57) reported that polyclonal antibodies against cancer-associated PCNA (caPCNA), which can serve as a diagnostic marker of breast cancer, have been developed. Therefore, further investigation is necessary to clarify the underlying biological links between PCNA and BC.

TOP2A is an essential nuclear enzyme involved in DNA replication, and its expression is decreased at the end of mitosis and increased during the $\mathrm{S}$ to $\mathrm{G} 2 / \mathrm{M}$ phases in bladder 

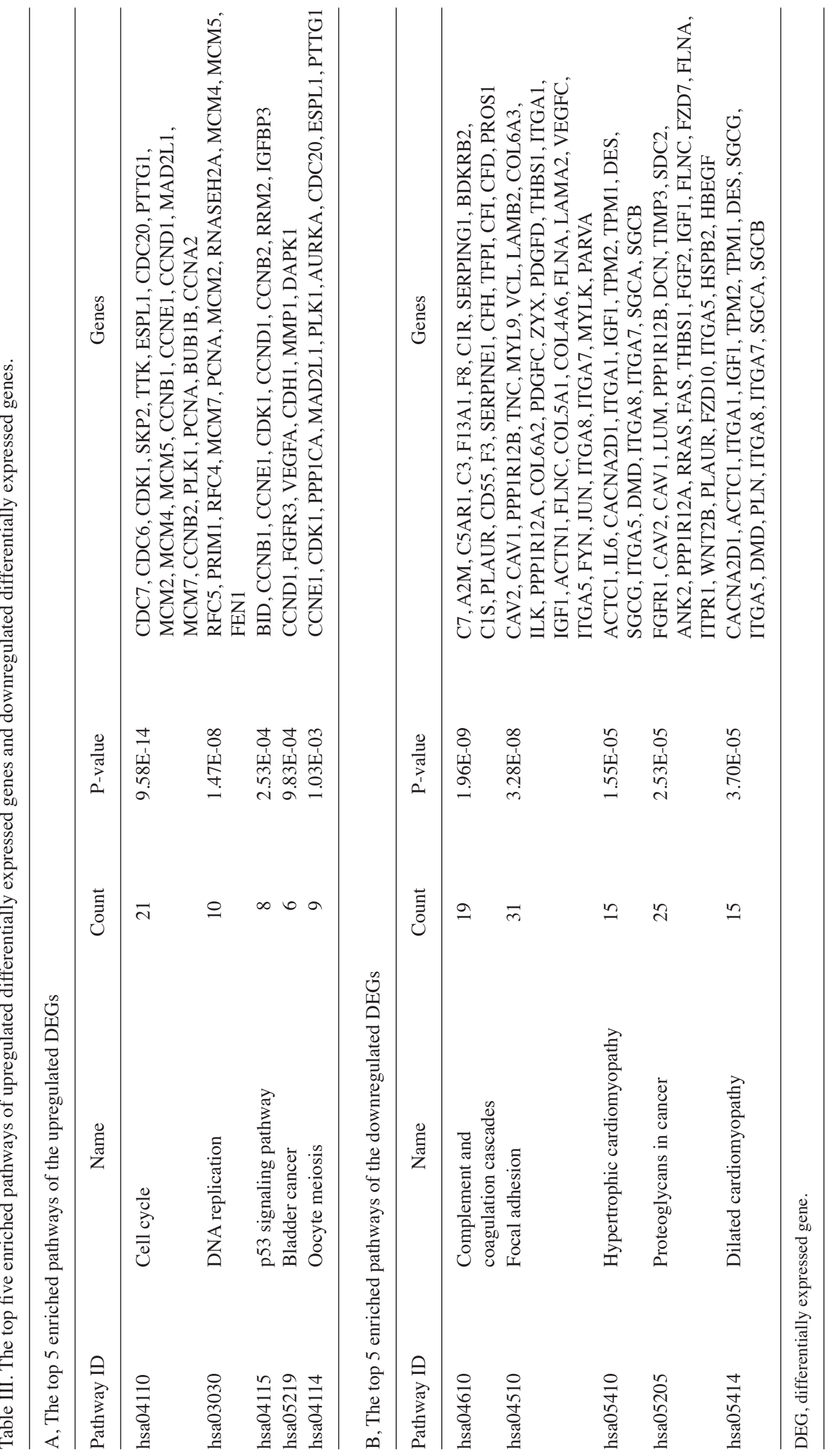
A

\begin{tabular}{|c|c|c|c|c|}
\hline Module & Name & Count & P-value & Genes \\
\hline \multirow{4}{*}{ Module 1} & Cell cycle & 11 & $8.84 \mathrm{E}-09$ & $\begin{array}{l}\text { CCNB1, CCND1, MAD2L1, CCNB2, PLK1, SKP2, } \\
\text { ESPL1, PTTG1, CCNA2, MCM5, WEE1 }\end{array}$ \\
\hline & Pathways in cancer & 11 & $2.94 \mathrm{E}-04$ & $\begin{array}{l}\text { BMP4, CKS1B, IL6, CCND1, CXCR4, PPARG, } \\
\text { CKS2, SKP2, LPAR1, BDKRB2, CXCL12 }\end{array}$ \\
\hline & FoxO signaling pathway & 7 & 2.99E-04 & CCNB1, IL6, CCND1, SIPR1, CCNB2, PLK1, SKP2 \\
\hline & Cell cycle & 11 & $2.26 \mathrm{E}-12$ & $\begin{array}{c}\mathrm{CDC} 7, \mathrm{CCNE} 1, \mathrm{CDK} 1, \mathrm{CDC} 6, \mathrm{MCM} 7, \mathrm{PCNA}, \mathrm{TTK}, \\
\text { BUB1B, CDC20, } \mathrm{MCM} 2, \mathrm{MCM} 4\end{array}$ \\
\hline
\end{tabular}

\begin{tabular}{ccccc} 
Module 2 & $\begin{array}{c}\text { Complement and } \\
\text { coagulation cascades } \\
\text { DNA replication }\end{array}$ & 5 & $6.99 \mathrm{E}-05$ & A2M, F13A1, SERPING1, CFD, PROS1 \\
& 4 & $2.14 \mathrm{E}-04$ & MCM7, PCNA, MCM2, MCM4 \\
\hline PI3K-Akt signaling pathway & 13 & $8.38 \mathrm{E}-08$ & IGF1, NR4A1, KIT, FGF2, COL5A1, COL4A6, \\
& & & & CSF1 R \\
Module 3 & & & SDC1, TNC, ITGA8, COL6A3, ITGA7, COL6A2, \\
& ECM-receptor interaction & 8 & $2.44 \mathrm{E}-07$ & COL5Al, COL4A6
\end{tabular}

\begin{tabular}{cccc} 
Focal adhesion & 9 & $8.03 \mathrm{E}-06$ & TNC, ITGA8, COL6A3, ITGA7, ILK, COL6A2, \\
& & IGF1, COL5A1, COL4A6 \\
\hline
\end{tabular}

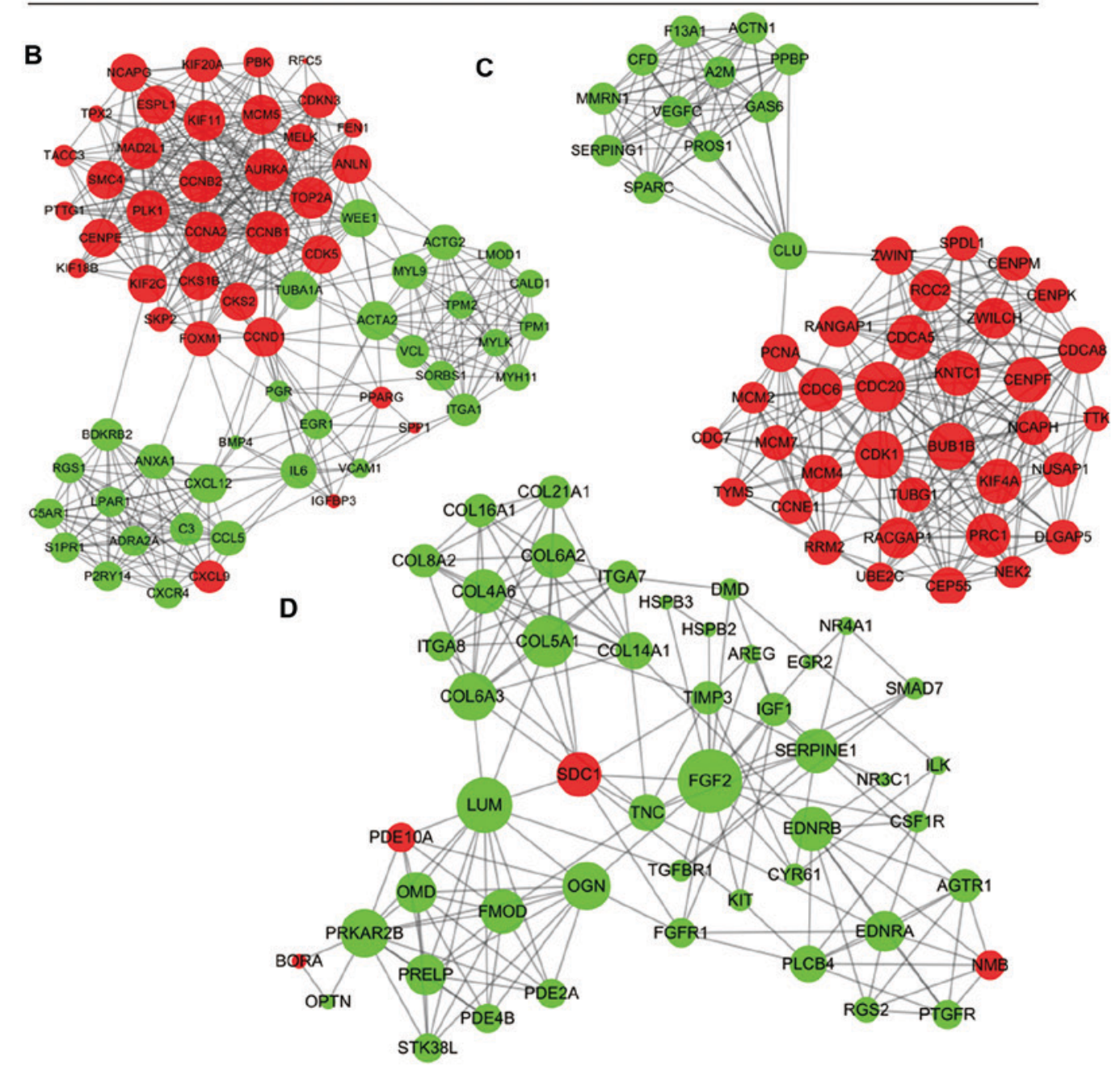

Figure 4. Top 3 modules from the PPI network. (A) The top 3 significant modules were selected. (B) Module 1 of DEGs from the PPI network; (C) module 2 of DEGs from the PPI network; and (D) module 3 of DEGs from the PPI network. PPI, protein-protein interaction; DEG, differentially expressed gene. 
urothelial carcinoma (58). Many studies have reported that the expression of TOP2A is increased in skin, breast, brain, ovarain and small cell lung cancers, and such increased expression is associated with shortened survival (59-63). Overexpression of TOP2A has been demonstrated to be related to recurrence and increased risk of death (64), and with late-stage BC (65). Lindén et al (66) reported that TOP2A could serve as a vital urinary biomarker candidate for BC. However, further investigation is required to elucidate the exact mechanism of action of TOP2A in the development and progression of BC.

The module analysis in the PPI network demonstrated that the development of $\mathrm{BC}$ was associated with the cell cycle signaling pathway and PI3K-Akt signaling pathway. It is well known that the cell cycle signaling pathway plays a key role in controlling the normal progression of the cell cycle. In the entire cell cycle regulatory network, abnormalities in various types of molecules can affect cell proliferation and apoptosis, potentially leading to uncontrolled cell growth and ultimately causing tumors. Akt plays a central role in the signaling pathways involved in cell growth, proliferation, angiogenesis, metabolism, apoptosis and migration $(67,68)$, and has already been found to be associated with cancer (69). Many studies have identified PI3K/Akt overexpression and activation in a variety of tumor tissues, such as ovarian cancer, colorectal cancer, lymphoma, pancreatic cancer, non-small cell lung cancer, lymphoma and gastric cancer (70-75). Therefore, blocking the cell cycle and inhibiting the PI3K-AKT signaling pathway are promising approaches for therapeutic intervention in $\mathrm{BC}$ patients.

In conclusion, the current study aimed to identify DEGs involved in the progression of $\mathrm{BC}$ via comprehensive bioinformatics analysis. This study provides several key genes and pathways for future investigation into the mechanisms and biomarkers of BC. However, a lack of experimental verification is a limitation of this study. Further experimental research is necessary to investigate the pathogenic mechanism of BC.

\section{Acknowledgements}

The authors would like to thank Mr. Weipeng Zheng at the Department of Orthopedics, Guangzhou First People's Hospital, Guangzhou Medical University (Guangzhou, China) for his assistance in the use of $\mathrm{R}$ programming language.

\section{Funding}

The present study was supported by Guangzhou Science and Technology Project of China (grant no. 201510010272).

\section{Availability of data and materials}

The datasets of gene expression profiles for bladder cancer (GSE7476) are available in the GEO on the NCBI website (http://www.ncbi.nlm.nih.gov/geo).

\section{Authors' contributions}

ZH and FT conceived and coordinated the study. FT and ZH designed methods, analyzed the data, interpreted the results and wrote and reviewed the manuscript. HL, YC and ZL co-analyzed and interpreted the data regarding the functional and pathway enrichment and PPI network construction. GZ and HW downloaded the gene expression profile from the GEO and interpreted the primary data regarding bladder cancer. All authors contributed to, read and approved the manuscript.

\section{Ethics approval and consent to participate}

Not applicable.

\section{Consent for publication}

Not applicable.

\section{Competing interests}

The authors declare that they have no competing interest.

\section{References}

1. Antoni S, Ferlay J, Soerjomataram I, Znaor A, Jemal A and Bray F: Bladder cancer incidence and mortality: A global overview and recent trends. Eur Urol 71: 96-108, 2017.

2. Torre LA, Bray F, Siegel RL, Ferlay J, Lortet-Tieulent J and Jemal A: Global cancer statistics, 2012. CA Cancer J Clin 65: 87-108, 2015.

3. Pinto IG: Systemic therapy in bladder cancer. Indian J Urol 33: 118-126, 2017.

4. Burger M, Catto JW, Dalbagni G, Grossman HB, Herr H, Karakiewicz P, Kassouf W, Kiemeney LA, La Vecchia C, Shariat S and Lotan Y: Epidemiology and risk factors of urothelial bladder cancer. Eur Urol 63: 234-241, 2013.

5. Choueiri TK and Raghavan D: Chemotherapy for muscle-invasive bladder cancer treated with definitive radiotherapy: Persisting uncertainties. Nat Clin Pract Oncol 5: 444-454, 2008.

6. Forbes SA, Bindal N, Bamford S, Cole C, Kok CY, Beare D, Jia M, Shepherd R, Leung K, Menzies A, et al: COSMIC: Mining complete cancer genomes in the catalogue of somatic mutations in cancer. Nucleic Acids Res 39 (Database Issue): D945-D950, 2011.

7. Goebell PJ and Knowles MA: Bladder cancer or bladder cancers? Genetically distinct malignant conditions of the urothelium. Urol Oncol 28: 409-428, 2010.

8. Cancer Genome Atlas Research Network: Comprehensive molecular characterization of urothelial bladder carcinoma. Nature 507: 315-322, 2014.

9. Guo W, Xie L, Zhao L and Zhao Y: mRNA and microRNA expression profiles of radioresistant NCI-H520 non-small celllung cancer cells. Mol Med Rep 12: 1857-1867, 2015.

10. Mengual L, Burset M, Ars E, Lozano JJ, Villavicencio H, Ribal MJ and Alcaraz A: DNA microarray expression profiling of bladder cancer allows identification of noninvasive diagnostic markers. J Urol 182: 741-748, 2009.

11. Smyth GK: Limma: Linear models for microarray data. Bioinform Comput Biol Sol Using R Bioconduct. Springer: pp397-420, 2005.

12. Hardcastle TJ: Generalized empirical Bayesian methods for discovery of differential data in high-throughput biology. Bioinformatics 32: 195-202, 2016.

13. Huang da W, Sherman BT and Lempicki RA: Systematic and integrative analysis of large gene lists using DAVID bioinformatics resources. Nat Protoc 4: 44-57, 2009.

14. Stelzl U, Worm U, Lalowski M, Haenig C, Brembeck FH, Goehler H, Stroedicke M, Zenkner M, Schoenherr A, Koeppen S, et al: A human protein-protein interaction network: A resource for annotating the proteome. Cell 122: 957-968, 2005.

15. Von Mering C, Huynen M, Jaeggi D, Schmidt S, Bork P and Snel B: STRING: A database of predicted functional associations between proteins. Nucleic Acids Res 31: 258-261, 2003.

16. Szklarczyk D, Franceschini A, Kuhn M, Simonovic M, Roth A, Minguez P, Doerks T, Stark M, Muller J, Bork P, et al: The STRING database in 2011: Functional interaction networks of proteins, globally integrated and scored. Nucleic Acids Res 39 (Database Issue): D561-D568, 2011. 
17. Bandettini WP, Kellman P, Mancini C, Booker OJ, Vasu S, Leung SW, Wilson JR, Shanbhag SM, Chen MY and Arai AE: MultiContrast delayed enhancement (MCODE) improves detection of subendocardial myocardial infarction by late gadolinium enhancement cardiovascular magnetic resonance: A clinical validation study. J Cardiovasc Magn Reson 14: 83, 2012.

18. Dai QS, He HC, Cai C, Chen JH, Han ZD, Qin GQ, Liang YX and Zhong WD: Multicenter case-control study of the relationship between smoking and bladder cancer in China. Zhonghua Yi Xue Za Zhi 91: 2407-2410, 2011 (In Chinese).

19. Boccaccio $\mathrm{C}$ and Medico E: Cancer and blood coagulation. Cell Mol Life Sci 63: 1024-1027, 2006.

20. Gay LJ and Felding-Habermann B: Contribution of platelets to tumour metastasis. Nat Rev Cancer 11: 123-134, 2011. Falanga A Marchetti M and Vignoli A: Coagulation and cancer: Biological and clinical aspects. J Thromb Haemost 11: 223-233, 2013.

21. Zhao M, Li Z and Qu H: An evidence-based knowledgebase of metastasis suppressors to identify key pathways relevant to cancer metastasis. Sci Rep 5: 15478, 2015.

22. MacLachlan TK, Sang N and Giordano A: Cyclins, cyclin-dependent kinases and cdk inhibitors: Implications in cell cycle control and cancer. Crit Rev Eukaryot Gene Expr 5: 127-156, 1995.

23. Hanahan D and Weinberg RA: Hallmarks of cancer: The next generation. Cell 144: 646-674, 2011.

24. Dalbagni G, Presti J, Reuter V, Fair WR and Cordon-Cardo C: Genetic alterations in bladder cancer. Lancet 342: 469-471, 1993

25. Cote RJ, Dunn MD, Chatterjee SJ, Stein JP, Shi SR, Tran QC, $\mathrm{Hu}$ SX, Xu HJ, Groshen S, Taylor CR, et al: Elevated and absent $\mathrm{pRb}$ expression is associated with bladder cancer progression and has cooperative effects with p53. Cancer Res 58: 1090-1094, 1998.

26. Cordon-Cardo C, Wartinger D, Petrylak D, Dalbagni G, Fair WR, Fuks Z and Reuter VE: Altered expression of the retinoblastoma gene product: Prognostic indicator in bladder cancer. J Natl Cancer Inst 84: 1251-1256, 1992.

27. Bossis G, Malnou CE, Farras R, Andermarcher E, Hipskind R. Rodriguez M, Schmidt D, Muller S, Jariel-Encontre I and Piechaczyk M: Down-regulation of c-Fos/c-Jun AP-1 dimer activity by sumoylation. Mol Cell Biol 25: 6964-6979, 2005.

28. Hess J, Angel P and Schorpp-Kistner M: AP-1 subunits: Quarrel and harmony among siblings. J Cell Sci 117: 5965-5973, 2004.

29. Ye N, Ding Y, Wild C, Shen Q and Zhou J: Small molecule inhibitors targeting activator protein 1 (AP-1). J Med Chem 57 6930-6948, 2014.

30. Durchdewald M, Angel P and Hess J: The transcription factor Fos: A Janus-type regulator in health and disease. Histol Histopathol 24: 1451-1461, 2009.

31. Yao HQ, Peng Y, Zhong ZZ, He HX and Li ZH: Association of the expressions of platelet-derived growth factor receptor and c-Fos with the biological characteristics of bladder cancer. Di Yi Jun Yi Da Xue Xue Bao 24: 177-179, 2004.

32. Lan G, Yang L, Xie X, Peng L and Wang Y: MicroRNA-490-5p is a novel tumor suppressor targeting c-FOS in human bladder cancer. Arch Med Sci 11: 561-569, 2015.

33. Vleugel MM, Greijer AE, Bos R, van der Wall E and van Diest PJ: c-Jun activation is associated with proliferation and angiogenesis in invasive breast cancer. Human Pathol 37: 668-674, 2006.

34. Eferl R, Ricci R, Kenner L, Zenz R, David JP, Rath M and Wagner EF: Liver tumor development. c-Jun antagonizes the proapoptotic activity of p53. Cell 112: 181-192, 2003.

35. Huhe M, Liu S, Zhang Y, Zhang Z and Chen Z: Expression levels of transcription factors c-Fos and c-Jun and transmembrane protein HAb18G/CD147 in urothelial carcinoma of the bladder. Mol Med Rep 15: 2991-3000, 2017.

36. Hunter T and Pines J: Cyclins and cancer. II: Cyclin D and CDK inhibitors come of age. Cell 79: 573-582, 1994.

37. Zhong Z, Yeow WS, Zou C, Wassell R, Wang C, Pestell RG, Quong JN and Quong AA: Cyclin D1/cyclin-dependent kinase 4 interacts with filamin $\mathrm{A}$ and affects the migration and invasion potential of breast cancer cells. Cancer Res 70: 2105-2114, 2010.

38. Feakins RM, Nickols CD, Bidd $\mathrm{H}$ and Walton SJ: Abnormal expression of $\mathrm{pRb}, \mathrm{p} 16$, and cyclin D1 in gastric adenocarcinoma and its lymph node metastases: Relationship with pathological features and survival. Hum Pathol 34: 1276-1282, 2003.

39. Jovanovic IP, Radosavljevic GD, Simovic-Markovic BJ, Stojanovic SP, Stefanovic SM, Pejnovic NN and Arsenijevic NN Clinical significance of Cyclin D1, FGF3 and p21 protein expression in laryngeal squamous cell carcinoma. J BUON 19: 944-952, 2014.

40. Xu S, Gu G, Ni Q, Li N, Yu K, Li X and Liu C: The expression of AEG-1 and Cyclin D1 in human bladder urothelial carcinoma and their clinicopathological significance. Int J Clin Exp Med 8: 21222-21228, 2015.
41. Mao Q, Li Y, Zheng X, Yang K, Shen H, Qin J, Bai Y, Kong D, Jia $X$ and Xie L: Up-regulation of E-cadherin by small activating RNA inhibits cell invasion and migration in 5637 human bladder cancer cells. Biochem Biophys Res Commun 375: 566-570, 2008.

42. Cavallaro U, Schaffhauser B and Christofori G: Cadherins and the tumour progression: Is it all in a switch? Cancer Lett 176: 123-128, 2002.

43. Mialhe A, Levacher G, Champelovier P, Martel V, Serres M, Knudsen K and Seigneurin D: Expression of E-, P-, n-cadherins and catenins in human bladder carcinoma cell lines. J Urol 164: 826-835, 2000

44. Wheelock MJ, Shintani Y, Maeda M, Fukumoto Y and Johnson KR: Cadherin switching. J Cell Sci 121: 727-735, 2008.

45. Molinari M: Cell cycle checkpoints and their inactivation in human cancer. Cell Prolif 33: 261-274, 2000.

46. Hochegger H, Takeda S and Hunt T: Cyclin-dependent kinases and cell-cycle transitions: Does one fit all? Nat Rev Mol Cell Biol 9: 910-916, 2008

47. Möröy $\mathrm{T}$ and Geisen C: Cyclin E. Int J Bioch Cell Biol 36: 1424-1439, 2004

48. Sutherland RL and Musgrove EA: Cyclins and breast cancer. J Mammary Gland Biol Neoplasia 9: 95-104, 2004.

49. Lee MH and Yang HY: Regulators of G1 cyclin-dependent kinases and cancers. Cancer Metast Rev 22: 435-449, 2003.

50. Sávio AL, da Silva GN and Salvadori DM: Inhibition of bladder cancer cell proliferation by allyl isothiocyanate (mustard essential oil). Mutat Res 771: 29-35, 2015.

51. Kim SJ, Nakayama S, Miyoshi Y, Taguchi T, Tamaki Y, Matsushima T, Torikoshi Y, Tanaka S, Yoshida T, Ishihara H and Noguchi S: Determination of the specific activity of CDK1 and CDK2 as a novel prognostic indicator for early breast cancer. Ann Oncol 19: 68-72, 2008.

52. Leonardi E, Girlando S, Serio G, Mauri FA, Perrone G, Scampini S, Dalla Palma P and Barbareschi M: PCNA and Ki67 expression in breast carcinoma: Correlations with clinical and biological variables. J Clin Pathol 45: 416-419, 1992.

53. Al-Dhaheri WS, Hassouna I, Al-Salam S and Karam SM: Characterization of breast cancer progression in the rat. Ann N Y Acad Sci 1138: 121-131, 2008.

54. Bravo R, Frank R, Blundell PA and Macdonald-Bravo H: Cyclin/PCNA is the auxiliary protein of DNA polymerase. Nature 326: 515-517, 1987.

55. Nagase Y, Moriyama N, Kurimoto S, Tajima A, Higashihara E and Aso Y: Histochemical expression of proliferating cell nuclear antigen (PCNA) for pre and post chemotherapeutic bladder cancer. Nihon Hinyokika Gakkai Zasshi 86: 985-990, 1995 (In Japanese).

56. Inagaki T, Ebisuno S, Uekado Y, Hirano A, Hiroi A, Shinka T and Ohkawa T: PCNA and p53 in urinary bladder cancer: Correlation with histological findings and prognosis. Int J Urol 4: 172-177, 1997.

57. Malkas LH, Herbert BS, Abdel-Aziz W, Dobrolecki LE, Liu Y, Agarwal B, Hoelz D, Badve S, Schnaper L, Arnold RJ, et al: A cancer-associated PCNA expressed in breast cancer has implications as a potential biomarker. Proc Natl Acad Sci USA 103: 19472-19477, 2006.

58. Koren R, Kugel V, Dekel Y, Weissman Y, Livne PM and Gal R: Human DNA topoisomerase-IIalpha expression as a prognostic factor for transitional cell carcinoma of the urinary bladder. BJU Int 91: 489-492, 2003

59. Mu XC, Tran TA, Ross JS and Carlson JA: Topoisomerase II-alpha expression in melanocytic nevi and malignant melanoma. J Cutan Pathol 27: 242-248, 2000.

60. Holden JA and Townsend JJ: DNA topoisomerase II-alpha as a proliferation marker in astrocytic neoplasms of the central nervous system: Correlation with MIB1 expression and patient survival. Mod Pathol 12: 1094-1100, 1999.

61. Costa MJ, Hansen CL, Holden JA and Guinee D Jr: Topoisomerase II alpha: Prognostic predictor and cell cycle marker in surface epithelial neoplasms of the ovary and peritoneum. Int J Gynecol Pathol 19: 248-257, 2000.

62. Dingemans AM, Witlox MA, Stallaert RA, van der Valk P, Postmus PE and Giaccone G: Expression of DNA topoisomerase IIalpha and topoisomerase IIbeta genes predicts survival and response to chemotherapy in patients with small cell lung cancer. Clin Cancer Res 5: 2048-2058, 1999.

63. Depowski PL, Rosenthal SI, Brien TP, Stylos S, Johnson RL and Ross JS: Topoisomerase IIalpha expression in breast cancer: Correlation with outcome variables. Mod Pathol 13: 542-547, 2000 . 
64. Koren R, Kugel V, Dekel Y, Weissman Y, Livne PM and Gal R: Human DNA topoisomerase-IIalpha expression as a prognostic factor for transitional cell carcinoma of the urinary bladder. BJU Int 91: 489-492, 2003

65. Simon R, Atefy R, Wagner U, Forster T, Fijan A, Bruderer J, Wilber K, Mihatsch MJ, Gasser T and Sauter G: HER-2 and TOP2A coamplification in urinary bladder cancer. Int $\mathrm{J}$ Cancer 107: 764-772, 2003

66. Lindén M, Segersten U, Runeson M, Wester K, Busch C, Pettersson U, Lind SB and Malmström PU: Tumour expression of bladder cancer-associated urinary proteins. BJU Int 112: 407-415, 2013.

67. Manning BD and Cantley LC: AKT/PKB signaling: Navigating downstream. Cell 129: 1261-1274, 2007.

68. Song G, Ouyang G and Bao S: The activation of Akt/PKB signaling pathway and cell survival. J Cell Mol Med 9: 59-71, 2005.

69. Nicholson KM and Anderson NG: The protein kinase B/Akt signalling pathway in human malignancy. Cell Signal 14: 381-395, 2002.

70. Yousif NG: Fibronectin promotes migration and invasion of ovarian cancer cells through up-regulation of FAK-PI3K/Akt pathway. Cell Biol Int 38: 85-91, 2014.

71. Chen Y, Wang Z, Chang P, Xiang L, Pan F, Li J, Jiang J, Zou L, Yang L, Bian $\mathrm{Z}$ and Liang $\mathrm{H}$ : The effect of focal adhesion kinase gene silencing on 5-fluorouracil chemosensitivity involves an Akt/NF-kappaB signling pathway in colorectal carcrinomas. Int J Cancer 127: 195-206, 2010.
72. Xu ZZ, Xia ZG, Wang AH, Wang WF, Liu ZY, Chen LY and Li JM: Activation of the PI3K/AKT/mTOR pathway in diffuse large B cell lymphoma: Clinical significance and inhibitory effect of rituximab. Ann Hematol 92: 1351-1358, 2013.

73. Ripka S, Neesse A, Riedel J, Bug E, Aigner A, Poulsom R, Fulda S, Neoptolemos J, Greenhalf W, Barth P, et al: CUX1: Target of Akt signaling ang mediator of resisitance to apoptosis in pancreatic cancer. Gut 59: 1101-1110, 2010.

74. Cumberbatch M, Tang X, Beran G, Eckersley S, Wang X, Ellston RP, Dearden S, Cosulich S, Smith PD, Behrens C, et al: Identification of a subset of human non-small cell lung cancer patients with high PI3K $\beta$ and low PTEN expression, more prevalent in squamous cell carcinoma. Clin Cancer Res 11: 595-603, 2014.

75. Xie X, Tang B, Zhou J, Gao Q and Zhang P: Inhibition of the PI3K/Akt pathway increases the chemosensitivity of gastric cancer to vincristine. Oncol Rep 30: 773-782, 2013.

This work is licensed under a Creative Commons Attribution-NonCommercial-NoDerivatives 4.0 International (CC BY-NC-ND 4.0) License. 